\title{
Circadian and wakefulness-sleep modulation of cognition in humans
}

\author{
Kenneth P. Wright ${ }^{1 *}$, Christopher A. Lowry ${ }^{2}$ and Monique K. LeBourgeois ${ }^{3}$ \\ Department of Integrative Physiology, Sleep and Chronobiology Laboratory, University of Colorado, Boulder, CO, USA \\ ${ }^{2}$ Department of Integrative Physiology, Behavioral Neuroendocrinology Laboratory, University of Colorado, Boulder, CO, USA \\ ${ }^{3}$ Department of Integrative Physiology, Sleep and Development Laboratory, University of Colorado, Boulder, CO, USA
}

\section{Edited by:}

Joerg H. Stehle, Goethe University

Frankfurt, Germany

Reviewed by:

Andrew L. Gundlach, The University of Melbourne, Australia

Urs Albrecht, University of Fribourg,

Switzerland

*Correspondence:

Kenneth P. Wright, Department of

Integrative Physiology, University of

Colorado Boulder, Boulder, CO

80309-0354, USA.

e-mail:kenneth.wright@

colorado.edu
Cognitive and affective processes vary over the course of the $24 \mathrm{~h}$ day. Time of day dependent changes in human cognition are modulated by an internal circadian timekeeping system with a near- $24 \mathrm{~h}$ period. The human circadian timekeeping system interacts with sleep-wakefulness regulatory processes to modulate brain arousal, neurocognitive and affective function. Brain arousal is regulated by ascending brain stem, basal forebrain (BF) and hypothalamic arousal systems and inhibition or disruption of these systems reduces brain arousal, impairs cognition, and promotes sleep. The internal circadian timekeeping system modulates cognition and affective function by projections from the master circadian clock, located in the hypothalamic suprachiasmatic nuclei (SCN), to arousal and sleep systems and via clock gene oscillations in brain tissues. Understanding the basic principles of circadian and wakefulness-sleep physiology can help to recognize how the circadian system modulates human cognition and influences learning, memory and emotion. Developmental changes in sleep and circadian processes and circadian misalignment in circadian rhythm sleep disorders have important implications for learning, memory and emotion. Overall, when wakefulness occurs at appropriate internal biological times, circadian clockwork benefits human cognitive and emotion function throughout the lifespan. Yet, when wakefulness occurs at inappropriate biological times because of environmental pressures (e.g., early school start times, long work hours that include work at night, shift work, jet lag) or because of circadian rhythm sleep disorders, the resulting misalignment between circadian and wakefulness-sleep physiology leads to impaired cognitive performance, learning, emotion, and safety.

Keywords: circadian phase, sleep homeostasis, performance, forced desynchrony, circadian sleep disorders
Cognitive and affective processes vary with time of day. Brain and behavioral mechanisms that underlie this variation include prior amount of wakefulness, prior sleep history and internal circadian timing. We therefore begin by reviewing central nervous system processes that regulate brain arousal as these processes are involved in modulating neurocognitive and neuro-affective function. Brain arousal is modulated across the $24 \mathrm{~h}$ day to a large extent by active brain processes that promote wakefulness and sleep. Evidence of clock gene expression in brain cells outside of the suprachiasmatic nuclei (SCN) suggests a fundamental role of circadian clocks in brain function at the cellular level. Understanding the modulation of cognition by these processes provides perspective on the complex neurophysiological regulation of cognition in humans, including how the circadian and wakefulness-sleep systems interact. We then discuss the importance of proper alignment between wakefulness-sleep and circadian systems for promoting optional cognitive function. The negative influence of circadian misalignment (e.g., sleep and wakefulness occurring at an abnormal internal circadian time) on cognition is reviewed. Next, developmental changes in sleep and circadian systems are discussed as are the implications of these developmental changes for optimizing school start times to improve learning in school. Lastly, the contribution of circadian misalignment to the health and safety concerns associated with circadian sleep-wake disorders is discussed.

\section{REGULATION OF BRAIN AROUSAL WAKEFULNESS PROMOTING SYSTEMS}

Arousal systems located in the brain stem, basal forebrain (BF) and hypothalamus promote wakefulness while inhibition of these systems promotes sleep (Figure 1A). Ascending arousal systems are important for activating cortical neurons and promoting cognition. In addition, descending projections from the reticular formation are important for postural control and muscle tone facilitating neurobehavioral output (Schepens et al., 2008). Neurotransmitters involved in promoting wakefulness include acetylcholine, dopamine, glutamate, histamine, norepinephrine, orexin, and serotonin. Cholinergic cells, located in the pedunculopontine (PPT) and laterodorsal tegmental nuclei (LDT), project to the thalamus and excite thalamocortical cells 


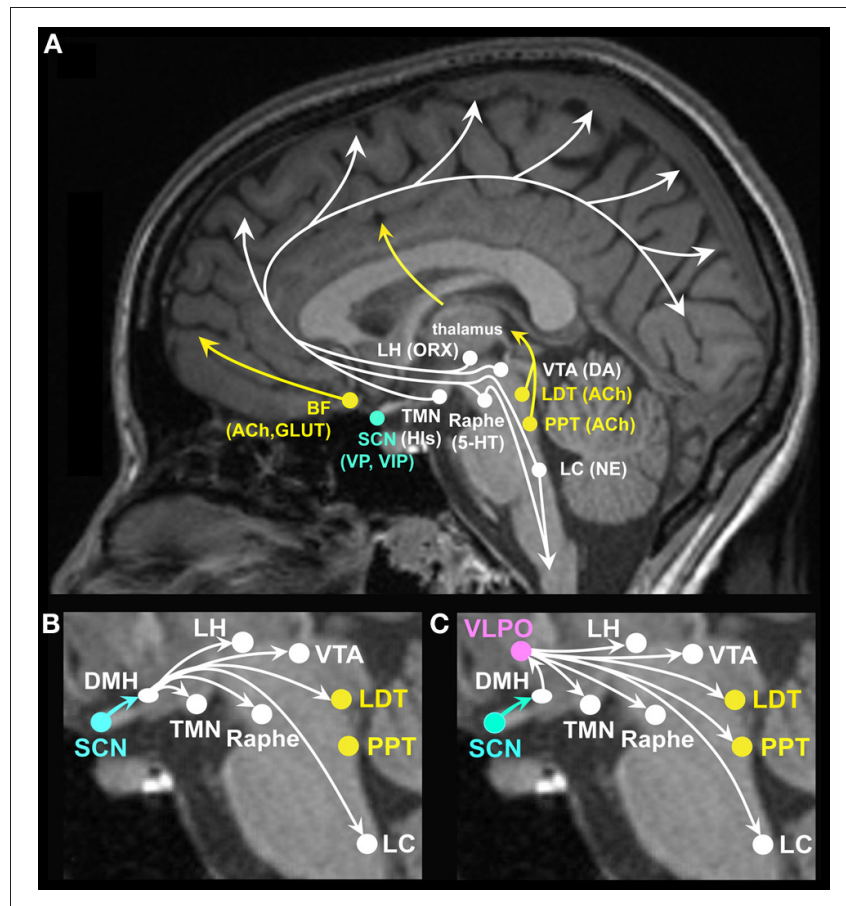

FIGURE 1 | (A) Brain arousal for neurocognitive and neuro-affective function is promoted by ascending brain stem, forebrain and hypothalamic projections to the cortex and midbrain. Neurotransmitter and neuropeptide systems involved in brain arousal and therefore in cognitive and affective function include the monoaminergic neurotransmitters histamine (His) from the tuberomammillary nucleus (TMN), norepinephrine (NE) from the locus coeruleus (LC), serotonin $(5-H T)$ from the midbrain raphe nuclei, dopamine (DA) from the ventral tegmental area (VTA), and substantia nigra (not shown); the cholinergic neurotransmitter acetylcholine (ACh) from the basal forebrain (BF) and the pedunculopontine (PPT), and laterodorsal tegmental nuclei (LDT); the peptide orexin (ORX), also referred to as hypocretin, from the lateral hypothalamus (LH); the excitatory amino acids glutamate (GLUT) and aspartate; vasopressin (VP), and vasoactive intestinal polypeptide (VIP) from the suprachiasmatic nuclei (SCN). (B) The master circadian clock located in the SCN has modulatory input to many of the ascending arousal pathways, some through direct projections from the SCN (not labeled, see text) and many through indirect projections relayed by the dorsomedial hypothalamus (DMH). Through such projections, the SCN can modulate circadian rhythms in brain arousal to promote wakefulness. (C) The SCN has modulatory input to the sleep systems via relay projections to the $\mathrm{DMH}$, onto the sleep promoting VLPO as well as midbrain and brain stem arousal systems. Through such projections, the SCN can modulate circadian rhythms in brain arousal to promote sleep.

facilitating arousal and information transfer to the cerebral cortex (McCormick and Bal, 1997). Cholinergic cells, located in neurons in the BF, project to the cortex to promote behavioral and cortical arousal (Steriade, 1992; Alam et al., 1999; Strecker et al., 2000). In general, firing rates of cholinergic neurons are higher during wakefulness than sleep (Datta and Siwek, 2002; Jones, 2005; McCarley, 2007). Dopaminergic neurons, located primarily in the substantia nigra and ventral tegmental areas, project to the striatum and frontal cortex, which when activated are important for behavioral arousal, reward seeking, and movement. Dopamine neurons show similar firing rates across sleep-wakefulness states (Shouse et al., 2000), yet inputs to dopamine neurons from other arousal systems may influence sleep and wakefulness (Monti and Monti, 2007). Glutamate and aspartate are excitatory amino acids localized within many neurons projecting to the cerebral cortex, the forebrain and brainstem. Glutamate, especially from the BF, is released in the largest amounts during wakefulness and its antagonists produce sleep (Nitz and Siegel, 1997). Histamine neurons localized in the tuberomammillary nucleus of the caudal hypothalamus provide excitatory input to the cerebral cortex promoting memory and feeding behaviors (Kohler et al., 2011; Passani et al., 2011). Histamine also appears to have a role in emotion and addiction-related behaviors (Yanai and Tashiro, 2007; Brabant et al., 2010). Histamine neuron firing rates are high during wakefulness and low during sleep (Brown et al., 2001; Jones, 2005). Norepinephrine (noradrenergic) neurons, localized primarily in the locus coeruleus (LC), project to the forebrain and cerebral cortex and are involved in attention, enhancing cortical activation and behavioral and emotional arousal (Greene et al., 2009; Tully and Bolshakov, 2010). Norepinephrine neurons also project to motor neurons providing excitatory drive to the motor neuron pool and therefore enhanced neuromuscular activity. Locus coeruleus neurons show higher firing rates during wakefulness than during sleep (Aston-Jones and Bloom, 1981; Steriade, 1992). Orexin/hypocretin cells localized in the lateral hypothalamus ( $\mathrm{LH}$ ) project to widespread areas of the brain stem, thalamus, hypothalamus and cerebral cortex (de Lecea et al., 1998; Peyron et al., 1998; Date et al., 1999) promoting brain arousal including emotional arousal (Hagan et al., 1999; Jones, 2008; Johnson et al., 2010). Orexin neurons show highest firing rates during waking, especially during movement, discharge less in quiet waking and are lowest during sleep (Jones, 2008). Serotonin neurons, localized in the brain stem raphe nuclei (RN) project to the cortex and spinal cord to promote brain, emotional and neuromuscular arousal (Lowry et al., 2010). Many serotonergic neurons themselves are under stimulatory control by other arousal-promoting systems, such as norepinephrine, histamine, and orexin (Sakai and Crochet, 2001; Brown et al., 2002; Liu et al., 2002; Soffin et al., 2004; Takahashi et al., 2005). The serotonergic neurons involved in promotion of brain arousal are likely to represent a subset of the total population of serotonergic neurons, as serotonergic neurons are topographically and functionally heterogeneous (Lowry et al., 2008; Hale and Lowry, 2011). Serotonergic neurons in the ventral part of the dorsal raphe nucleus, which project heavily to cortical and sensorimotor areas, are likely to play an important role in cortical and behavioral arousal (Lowry et al., 2008; Hale and Lowry, 2011). These neurons show higher firing rates during wakefulness than during sleep (Sakai and Crochet, 2001; Abrams et al., 2004; Lowry et al., 2010). Figure 1 shows that projections from the LDT and PPT excite thalamocortical pathways; projections from brain stem LC and midbrain RN excite cortical, midbrain and spinal neuromuscular pathways. Projections from the LH excite cortical, midbrain and brain stem arousal pathways and play an important role in stabilizing the state of wakefulness. Projections from the BF excite cortical and midbrain arousal pathways. Collectively, the systems discussed above promote brain arousal and disruption of one or more of these 
systems will have negative influences on cognitive and affective function.

\section{SLEEP PROMOTING SYSTEMS}

Sleep promoting systems include neurons in the median preoptic nucleus of the hypothalamus (MnPN) (Uschakov et al., 2007; Hsieh et al., 2011) that increase firing rates prior to sleep onset and sleep active neurons in the ventrolateral preoptic area of the hypothalamus (VLPO) (Saper et al., 2005; Szymusiak et al., 2007; Saper et al., 2010). A number of sleep factors have been reported to promote sleep and be part of the natural sleep process. These factors include but are not limited to the neuromodulator adenosine and immune cytokines (Krueger et al., 2011). Adenosine is a sleep factor that reflects homeostatic sleep drive, rising with increased time awake, dissipating during sleep, and influencing brain regulatory wakefulness/sleep centers (Rainnie et al., 1994; Porkka-Heiskanen et al., 1997; Chamberlin et al., 2003). Specifically, adenosine builds up throughout the day in the $\mathrm{BF}$ and dissipates with sleep. Adenosine binds to adenosine receptors located on the VLPO, MnPN, orexin and non-orexin LH cells, and in the cortex to promote sleep (Elmenhorst et al., 2007; Szymusiak and McGinty, 2008; Rai et al., 2010). Activation of the MnPN and VLPO leads to GABA release quieting activity of ascending arousal systems. Some proinflammatory cytokines released from immune cells are also reported to increase with sleep loss, play a role in promoting the natural sleep process and are associated with increased sleepiness (Vgontzas et al., 2004; Frey et al., 2007; Krueger et al., 2011). Activities of wakefulness and sleep neurons discussed above not only vary between wakefulness and sleep as described, but many also vary in their activity between NREM and REM sleep. See (Jones, 2005; Saper et al., 2005; Fuller et al., 2007; Szymusiak et al., 2007; Szymusiak and McGinty, 2008; Saper et al., 2010) for reviews on brain control of NREM and REM sleep states.

\section{MUTUAL INHIBITORY NATURE OF WAKEFULNESS AND SLEEP PROMOTING SYSTEMS}

The major monoaminergic arousal systems each send projections to the VLPO (Chou et al., 2002) and these arousal cell groups actively inhibit the VLPO to promote wakefulness. Orexin neurons contribute to the activation of arousal systems and help to maintain wakefulness. Activity of orexin neurons are influenced by other neurons including excitatory glutamatergic and inhibitory GABAergic inputs from BF and excitatory norepinephrine inputs from the LC (Bayer et al., 2005; Henny and Jones, 2006; Hassani et al., 2010). Arousal systems in turn are inhibited through GABAergic and galaninergic projections from the VLPO and MnPN (Lu et al., 2000; Szymusiak and McGinty, 2008; Saper et al., 2010) to promote sleep. Although transitions between sleep and wakefulness appear rapid (Wright et al., 1995), cognition is initially impaired quite severely upon the transition from sleep to wakefulness (Dinges, 1990; Wertz et al., 2006). This phenomenon, called sleep inertia, is associated with rapid activation of brain stem arousal systems noted above but a delayed activation of cortical regions, especially the prefrontal cortex (Balkin et al., 2002). The neurophysiological process of awakening is less well characterized than is the promotion of sleep.

\section{CIRCADIAN MODULATION OF BRAIN AROUSAL}

The circadian timekeeping system is composed of a self-sustained master circadian clock, located in the SCN of the hypothalamus, as well as circadian clocks in tissues outside of the SCN. Rhythmic clock gene expression during light-dark cycles has been described in some brain regions involved in cognition, affect, and arousal pathways including prefrontal, parietal and cingulate cortex, amygdala, caudate-putamen, nucleus accumbens, hippocampus, ventral tegmental area (VTA), and dorsomedial hypothalamus (DMH) (Namihira et al., 1999; Masubuchi et al., 2000; Wakamatsu et al., 2001; Abe et al., 2002; Guilding and Piggins, 2007; Guilding et al., 2009; Li et al., 2009; Jilg et al., 2010; Cermakian et al., 2011; Hughes et al., 2011). Many, but not all brain regions appear to show rhythmic clock gene expression (e.g., Abe et al., 2002; Guilding and Piggins, 2007). Emerging evidence indicates that altered clock gene function is associated with altered learning at cellular and behavior levels (e.g., long-term potentiation and trace-fear conditioning; Wang et al., 2009). The contribution of brain clocks outside of the SCN for human cognition remains to be determined, but it has been hypothesized that disrupted synchronization among brain clocks may contribute to cognitive and emotional impairments in Alzheimer's disease (Cermakian et al., 2011) and psychiatric disorders (Rosenwasser, 2010).

The SCN modulates human physiology and behavior with a near- $24 \mathrm{~h}$ periodicity (i.e., the duration to complete one cycle is approximately $24 \mathrm{~h}$ ) (Wright et al., 2001; Duffy et al., 2011). Efferents from the SCN project to many of the brain regions involved in promoting wakefulness and sleep (Figures 1B and 1C) (Chou et al., 2002; Deurveilher and Semba, 2003, 2005). For example, vasopressin (VP) and vasoactive intestinal polypeptide (VIP) containing SCN efferents project to the DMH (Dai et al., 1997; Deurveilher and Semba, 2005; Kalsbeek et al., 2010), which relays projections to ascending arousal norepinephrine LC neurons, cholinergic LDT neurons, dopamine VTA neurons, and serotonergic raphe neurons (Aston-Jones et al., 1991, 2001; Luo and Aston-Jones, 2009). SCN efferents also indirectly project to wakefulness-promoting orexinergic and histaminergic neurons in the LH, and to the sleep active VLPO (Chou et al., 2003; Saper et al., 2005). Efferents from the SCN project to the subparaventricular hypothalamic zone (Leak and Moore, 2001; Chou et al., 2003; Saper et al., 2005), which in turn projects to the preoptic area of the hypothalamus, which, in addition to its role in sleep regulation, is involved in thermoregulation (Szymusiak et al., 2007). SCN efferents also indirectly project to the paraventricular nucleus of the hypothalamus and modulate sympathetic nervous system activity and endocrine physiology. For example, the SCN regulates the circadian rhythm in the pineal hormone melatonin (Teclemariam-Mesbah et al., 1999; Rajaratnam et al., 2009b). Once secreted by the pineal gland, melatonin initiates a cascade of physiological events that are sleep promoting in humans. Melatonin binding to melatonin receptors in the SCN reduces SCN neuronal firing rates and this is hypothesized to quiet the circadian brain arousal signal and therefore promote sleep. Melatonin and melatonin receptor agonists also affect other physiological systems that promote sleep, such as reducing core body temperature and increasing peripheral heat loss (Krauchi et al., 
1997; van Someren, 2000; Wyatt et al., 2006; Rajaratnam et al., 2009a; Markwald et al., 2010). Furthermore, the SCN may modulate cognition through control of the circadian rhythm in body temperature as clock genes in extra-SCN cells are synchronized by temperature oscillations within the circadian temperature range (Buhr et al., 2010) and since body temperature level can influence human cognition (Wright et al., 2002). The SCN may also modulate wakefulness and sleep via circadian modulation of sleep promoting immune cytokines.

Circadian misalignment, induced by shifts of the light-dark cycle simulating jet lag, is reported to be associated with internal desynchrony between clock gene expression in the SCN and peripheral tissues. For example, clock genes in the liver take longer to adjust to an advance of the light-dark cycle (Yamazaki et al., 2000). Similar internal desynchrony occurs between clock gene oscillations in the SCN and other brain regions (Abe et al., 2002) and thus brain desynchrony could contribute to disrupted cognitive function during circadian misalignment. Further research is needed to understand mechanisms by which circadian oscillations in brain tissues are synchronized. Circadian disruption associated with a failure to synchronize to a non- $24 \mathrm{~h}$ day length has also been shown to alter the structure of the prefrontal cortex and result in impaired cognitive function (Karatsoreos et al., 2011).

The circadian system also gates exposure to light which can have direct and indirect influences on cognition. For example, projections from intrinsically photosensitive retinal ganglion cells project to the SCN and directly to the dorsal raphe nucleus (Shen and Semba, 1994) and VLPO (Gooley et al., 2003; Hannibal and Fahrenkrug, 2004). Light exposure during wakefulness can thus modulate brain arousal through influence on sleep-wakefulness centers discussed above.

\section{NEUROCOGNITIVE AND NEURO-AFFECTIVE FUNCTION INTEGRATIVE CONTROL SYSTEMS OF COGNITION}

Cognition varies across the $24 \mathrm{~h}$ day, and the pattern of cognitive and affective function is driven by interactions between the three neurobiological processes discussed above: sleep inertia, homeostatic sleep drive and circadian phase. Figure 2 shows a typical pattern observed for working memory performance across a typical day of wakefulness followed by one night of total sleep deprivation. Immediately upon awakening, cognition is severely impaired due to sleep inertia. Over time, sleep inertia is dissipated and high levels of cognition are reached between $2-4 \mathrm{~h}$ awake. Cognition is then maintained at relatively high levels across the remainder of the typical waking day, with the exception of a midday dip or afternoon slump in cognition. If wakefulness is extended after habitual bedtime, cognition worsens and is impaired in the early morning hours. The current example shows that the influence of sleep inertia on cognition can be worse than that produced by one night of total sleep deprivation for working memory performance. Additional research is needed to compare the relative effects of sleep inertia and sleep loss on other measures of cognition. The individual contribution of sleep inertia, sleep homeostatic and circadian processes to the daily pattern of cognition can be modeled in forced desynchrony protocols that schedule sleep and wakefulness to occur

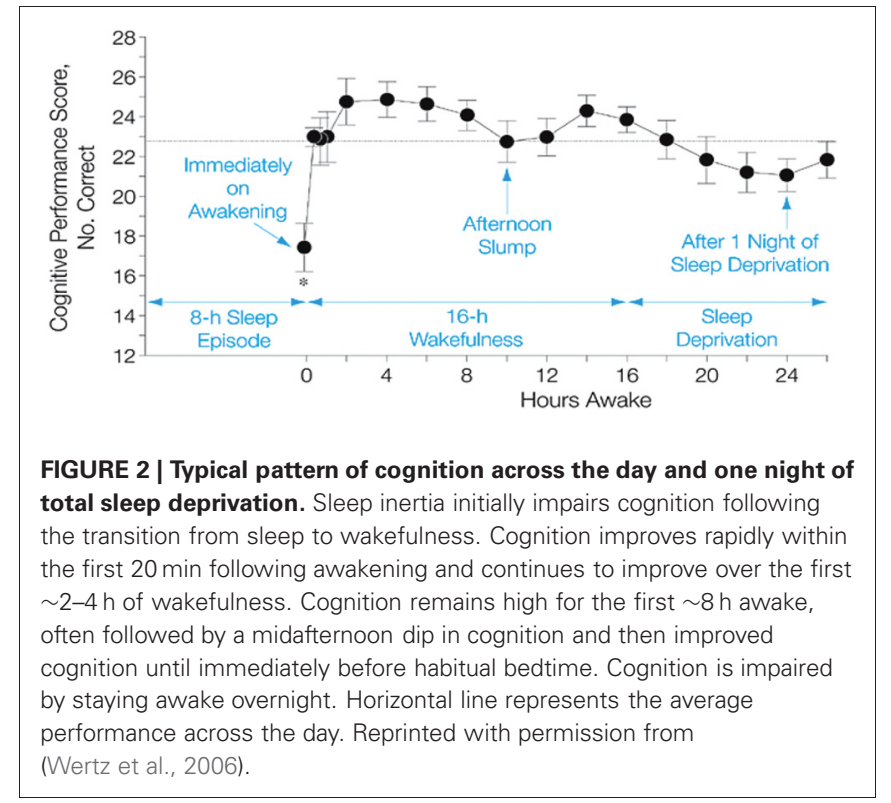

across the circadian cycle. To date, forced desynchrony studies have modeled the independent contribution of sleep homeostatic and circadian processes for vigilance, working memory, sleepiness and mood (Czeisler et al., 1994; Boivin et al., 1997; Wyatt et al., 2004; Lee et al., 2009; Murray et al., 2009; Cohen et al., 2010; Grady et al., 2010; Silva et al., 2010; Zhou et al., 2011a, 2012; Matthews et al., 2012). General findings from these studies indicate that alertness, vigilance, cognitive speed, memory, mood, and driving performance, degrade with time awake and cycle with circadian phase. Findings from forced desynchrony studies help to explain the typical daily pattern of cognition shown in Figure 2. Specifically, Figure 3 shows at habitual wake time, cognition is low because both sleep inertia and the circadian system reduce brain arousal. When sleep inertia is dissipated, cognition is high as the homeostatic drive for sleep is relatively low and the circadian system begins to promote brain arousal. As time awake progresses, homeostatic sleep drive builds and if it were not for an increase in circadian-driven brain arousal, performance would degrade across the waking day. The midday dip in cognition observed in many but not all studies may result because the circadian arousal signal was not yet strong enough to counter the level of homeostatic sleep drive, yet studies that manipulate circadian phase and sleep drive are needed to test the latter. During the habitual sleep episode both high homeostatic sleep drive at the beginning of the sleep episode and high circadian sleep drive at the end of the sleep episode promote sleep. When wakefulness is sustained into the habitual sleep time (sleep deprivation at night), brain arousal is low resulting in a vulnerable time of cognitive impairment. This typical daily pattern of cognition is dependent upon an appropriate relationship between sleep-wakefulness and internal circadian timing (Dijk and Czeisler, 1995; Hull et al., 2003; Zhou et al., 2011a). From a circadian perspective, cognition is best several hours prior to habitual sleep time and worst near habitual wake time. Sleep inertia has also been reported to vary 


\section{Interaction Between Sleep Homeostasis and Circadian Phase} Modulates Human Performance - Normal Phase Relationship

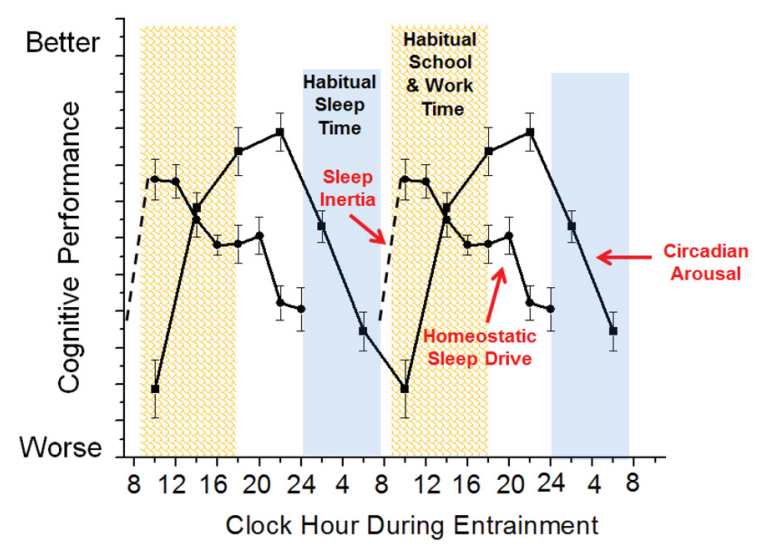

FIGURE 3 | Simplified model of wakefulness-sleep and circadian modulation of cognition. Data are double plotted and show individual contribution of sleep inertia (grogginess upon awakening from sleep), homeostatic sleep drive (time awake and prior sleep history) and circadian phase (internal biological time) modulation of cognitive function under typical conditions.

with circadian phase and prior wakefulness (Dinges, 1990; Scheer et al., 2008; Silva and Duffy, 2008), but additional work is needed to describe the individual contribution of sleep inertia to cognition. Predictions from this simple model shown in Figure 3 are relatively straightforward with respect to changes in the relationship between sleep drive and circadian phase. However, this model does not take into account that the sleep and circadian drives interact such that the amplitude of the circadian influence on cognition increases with homeostatic sleep drive. Specifically, cognition will be worse near the circadian low in brain arousal in the morning hours especially following a prolonged duration of wakefulness (Cohen et al., 2010; Grady et al., 2010). In addition, prior sleep history/chronic sleep loss interacts with circadian phase and duration of wakefulness to worsen cognition (Cohen et al., 2010; Zhou et al., 2011b). It has also been shown that vigilance impairments are cumulative with increased days of circadian misalignment (Wright et al., 2006; Lee et al., 2009; Cohen et al., 2010; Silva et al., 2010). Whereas tasks with learning curves either show continued improvement (Lee et al., 2009) or learning impairment (Wright et al., 2006) during chronic circadian misalignment. Additional research is necessary to determine how circadian and wakefulness-sleep systems individually contribute and interact to modulate higher cognitive functions as the forced desynchrony studies to date have focused on limited types of cognitive functions.

The interaction between sleep-wakefulness and circadian timing can help to understand differences in cognitive function between morning and evening types. Morning types go to bed and awaken at a later internal circadian time (Kerkhof and van Dongen, 1996; Duffy et al., 1999; Mongrain et al., 2004). Thus, their circadian rhythm in brain arousal occurs earlier helping to explain why they are more alert and perform better in the morning and are sleepier in the evening as compared to evening types. Conversely, evening types go to bed and awaken at an earlier circadian time. Thus, evening types awaken closer to the circadian nadir of brain arousal, making it more difficult to be awake in the morning, and are more alert and perform better in the evening as their circadian peak in brain arousal occurs later in the day as compared to morning types. Morningness-eveningness behavioral preferences (Duffy et al., 2001) and the relationship between internal circadian timing and habitual bedtime/environmental time (Wright et al., 2005; Gronfier et al., 2007; Duffy et al., 2011) are driven in part by the circadian period of the individuals circadian clock. Those individuals with shorter or faster periods are more likely to be morning types and those with longer or slower circadian periods are more likely to be evening types (Duffy et al., 2001). Findings from forced desynchrony studies also indicate that there are age related differences in performance during circadian misalignment, with young adults showing greater impairment in cognition than older adults (Silva et al., 2010).

\section{REAL WORLD CONSEOUENCES OF CIRCADIAN MISALIGNMENT CIRCADIAN MISALIGNMENT IMPAIRS COGNITION}

Misalignment between sleep and wakefulness schedules and the internal circadian timing system occurs in many occupational schedules in today's $24 \mathrm{~h}$ society (e.g., emergency medical and safety personnel, transportation, security and military personnel). There is substantial evidence that sleepiness and fatigue caused by circadian misalignment and associated sleep loss have been the primary causes of serious accidents and tragedies in industry and transportation (Horne and Reyner, 1995; Lyznicki et al., 1998; Horne et al., 2003; Barger et al., 2005). Each year, many transportation accidents are attributed to the operators falling asleep at the controls (Pack et al., 1995). In a recent study of medical residents, it was reported that chronic sleep loss combined with working during the circadian night impaired performance on the work shift, increased the risk of actual medical errors and increased the risk of falling asleep at the wheel while driving home (Landrigan et al., 2004; Lockley et al., 2004; Barger et al., 2005). The hper $3^{5 / 5}$ (human Period 3) gene polymorphism is associated with impaired performance during acute circadian misalignment of overnight sleep deprivation providing evidence of genetic contribution to individual differences in performance (Viola et al., 2007). The hper $3^{5 / 5}$ appears to be specific to cognitive impairment associated with circadian misalignment as no association with performance vulnerability was observed during the biological daytime under conditions of chronic sleep loss (Goel et al., 2009).

\section{CIRCADIAN MISALIGNMENT AND COGNITION IN CHILDREN AND ADOLESCENTS}

Although a growing literature from adults indicates the importance of circadian timing for cognitive processes, its role in children and adolescents is poorly understood. The first two decades of life represent a time of dramatic developmental change in brain structure and function associated with basic cognitive and affective function supporting life-long adaptation and learning (Stiles 
and Jernigan, 2010). Importantly, shifts in sleep and brain arousal enable children to stay awake and interact in their environment for longer and longer periods of time as they mature. For example, findings from longitudinal research suggest total $24 \mathrm{~h}$ sleep duration (reported time in bed) is about $13 \mathrm{~h}$ at 2 years, $11.5 \mathrm{~h}$ at 5 years, $9.9 \mathrm{~h}$ at 10 years, and $8.1 \mathrm{~h}$ at 16 years of age (Iglowstein et al., 2003). Afternoon sleep tendency unfolds in a U-shaped distribution, with high levels at ages 2-3 years, low levels in 8-9 year-olds, and moderate-to-high levels in 15-16 year-olds (Carskadon et al., 1980; Crosby et al., 2005). Unlike adults, the basic physiological processes (circadian and homeostatic) underlying regulation of sleep and alertness in children and adolescents are undergoing developmental change (Jenni and LeBourgeois, 2006). In the context of academic, family, and social demands, the developing interaction of these processes may place children and adolescents at high risk for problems in sustaining wakefulness during the day, falling asleep at an appropriate bedtime, and/or waking in the morning feeling rested and alert. Current findings in pre-pubertal and fully mature adolescents suggest the wellknown adolescent sleep phase delay is determined by changes in both systems. Specifically, a phase delay of about one hour in the internal circadian timekeeping system [Dim Light Melatonin Onset $(\mathrm{DLMO}) \sim 2030 \mathrm{~h}$ in prepubertal children; $\sim 2130 \mathrm{~h}$ in mature adolescents] and a slower accumulation of sleep pressure across the day interact to promote alertness at a later time in the evening in adolescents than in children (Jenni et al., 2005). Much less is known about the homeostatic and circadian processes in children under the age of 9 years and understanding developmental aspects of sleep and circadian rhythm physiology in young children represents an unmet need. Available findings indicate the internal timing of the circadian clock is earlier in preschool children (DLMO $\sim 1930 \mathrm{~h}$ ) than in school-age children and adolescents (Garlo et al., 2008).

Well-controlled studies of the cognitive effects of misalignment between circadian physiology and sleep-wakefulness times in children and adolescents are nascent. Nonetheless, several lines of research converge to suggest circadian misalignment may contribute to impaired cognition in young humans. First, early school start times are a well-known social demand requiring many teens to rise, attend class, and perform cognitively before the waking-promoting effects of the circadian system are fully realized (Carskadon et al., 1998). Findings from several studies have shown delayed school start times lead to more time in bed, improved mood, better grades, improved attendance rates, and reduced driving accidents (Wolfson et al., 2007; Owens et al., 2010; Wahlstrom, 2010; Vorona et al., 2011). Second, in older adolescents studied in a well-controlled $28 \mathrm{~h}$ constant routine protocol, sustained attention (short-term stability) increased across the daytime and decreased during the night (Valdez et al., 2010). Third, performance on executive function tasks varies with time of day, with adolescents performing better in the afternoon than in the morning (van der Heijden et al., 2010). These changes during adolescence may be related to a delay in the timing of the internal circadian clock, as well as chronic sleep loss. Finally, preschool children's readiness for school is strongly predicted by their weekend sleep phase, such that young children going to bed and waking later (midpoint of sleep) are more likely to perform poorly on cognitive tasks than those with early sleep phases (Crosby et al., 2006). Given success in school is largely dependent on key cognitive processes (e.g., attention, memory, executive function) and predicts long-term occupational, health, and academic outcomes, a greater emphasis on understanding circadian misalignment effects on cognition in childhood and adolescence is warranted.

As noted above, older adults appear to show smaller changes in cognitive function during circadian misalignment as compared to young adults (Silva et al., 2010). This finding is perhaps related to a reduced sensitivity to circadian and/or homeostatic sleep promoting drives with aging. As children and adolescents have a higher sleep pressure than adults, it is possible that children and adolescents may show even greater impairment than young adults during circadian misalignment. Additional research using circadian protocols is needed to examine the latter.

\section{CIRCADIAN MISALIGNMENT IN CIRCADIAN RHYTHM SLEEP-WAKE DISORDERS}

Circadian sleep disorders are often characterized by misalignment between internal circadian timekeeping and sleepwakefulness/environmental schedules (Sack et al., 2007a,b). A common symptom observed in patients with circadian sleep disorders is disturbed/inadequate sleep when sleep is desired. These disorders often cause excessive daytime sleepiness and fatigue. The most common circadian sleep disorders are Delayed Sleep Phase Disorder, Advanced Sleep Phase Disorder, Jet Lag, Non-24 H Sleep Wake Disorder, and Shift Work Disorder. These disorders have negative family, social, work, and health consequences. The type of circadian misalignment and the cognitive affective consequences associated with these disorders will be briefly described. More detailed discussion of these disorders can be found elsewhere (Lu and Zee, 2006; Sack et al., 2007a,b; Reid and Zee, 2009).

\section{Delayed and advanced sleep phase disorder types}

Delayed sleep phase is often associated with a later internal circadian brain arousal rhythm that promotes bedtimes and wake times that are later than desired or than are required by the patient because of imposed school or work schedules. Adolescents and young adults are most likely to present with delayed sleep phase. Patients with delayed sleep phase have difficulties falling asleep at a reasonable hour and have difficulties awakening and with cognitive functioning in the morning (Sack et al., 2007b) (Figure 4). Morning sleepiness especially interferes with their daily functioning and ability to cognitively perform in school. When responsibilities no longer dictate an early sleep schedule (e.g., summer vacation), the individual has no difficulty sleeping or awakening when the timing of the major sleep episode is delayed and the person is allowed to sleep in late. Figure 4 shows the desire to go to bed later and to sleep in later in the morning is related in part to a shift in internal circadian time, as represented by the delay in the timing of the circadian melatonin rhythm (red dashed line) as compared to normal (black solid line). This delay in circadian timing is associated with and may be the primary cause of sleep onset insomnia (i.e., attempts to go to sleep at an internal biological time when the 


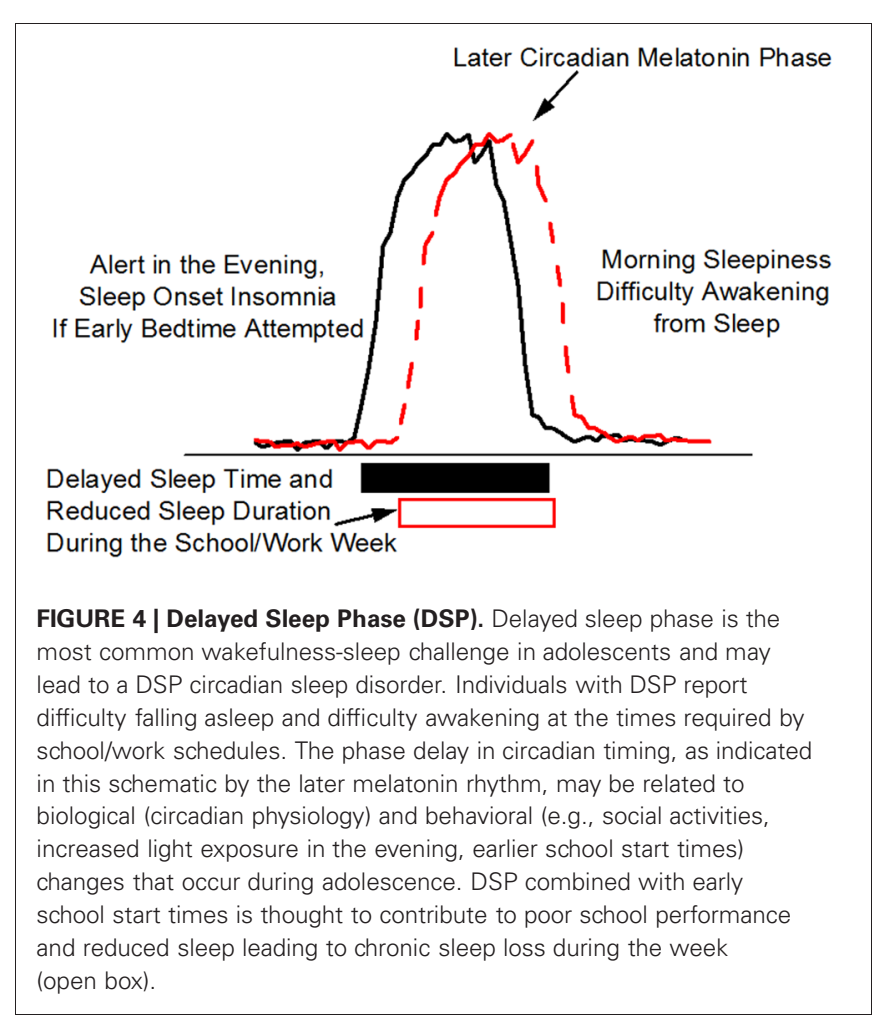

circadian clock is promoting wakefulness) and morning sleepiness (i.e., awakening at an internal biological time when the circadian clock is promoting sleep). Polymorphisms in the circadian clock gene hPer2 (human Period 2), the melatonin rate limiting enzyme gene AA-NAT (aralkylamine $\mathrm{N}$-acetyltransferase) and the clock protein phosphorylating enzyme CK1e (casein kinase I epsilon) have been reported to be associated with delayed sleep phase (Ebisawa et al., 2001; Hohjoh et al., 2003; Takano et al., 2004) indicating a genetic component to this disorder. Whether these clock gene polymorphisms are associated with impaired cognition when sleep occurs at the appropriate internal biological time is unknown. Delayed sleep phase is also associated with psychiatric comorbidities suggesting that circadian misalignment and associated sleep loss may increase expression of psychiatric disorders (Okawa and Uchiyama, 2007; Dagan et al., 1998). Opposite to the pattern observed in delayed sleep phase, advanced sleep phase is associated with an earlier internal circadian brain arousal rhythm that promotes bedtimes and wake times that are earlier than desired. Older adults are more likely to present with advanced sleep phase. Evening sleepiness most often interferes with social-cognitive functioning in advanced sleep phase type. If sleep and wakefulness occur at advanced times driven by the circadian clock, however, sleep is often of adequate duration and quality as is cognitive function. Individuals with a familial form of advances sleep phase carry a serine to glycine mutation in hPer2 (human Period 2) that is associated with a shorter period length of the circadian clock (Toh et al., 2001) promoting early bed and wake times. Treatment with appropriately timed bright light improves cognition and sleep in delayed and advance sleep phase (Sack et al., 2007b).

\section{Jet lag type}

Jet lag results from circadian misalignment caused by rapid travel across multiple time zones. During eastward jet travel, bed and wake times in the new time zone are earlier than the internal circadian time of the traveler and the opposite is true for westward travel. Sleep disruption and being awake at an inappropriate internal circadian time contribute to increased risk of accidents (e.g., drowsy driving) and impaired cognition (e.g., reduced cognitive ability during business meetings). Mood disruption has also been reported (Katz et al., 2001) and jet lag has been hypothesized to unmask existing psychiatric vulnerabilities (Katz, 2011). Jet lag symptoms persist for several days and can be shortened by properly timed exposure to light and darkness.

\section{Non-24 H}

Non-24 h occurs when the internal circadian clock fails to entrain or synchronize to the $24 \mathrm{~h}$ day. As a result, sleep and wakefulness may progressively move earlier or later each day depending on the circadian period of the patient's internal clock resulting in misalignment to environmental time (Wright et al., 2008; Uchiyama and Lockley, 2009). Alternatively, non-24 h patients may maintain a fixed wakefulness-sleep schedule and experience cyclical patterns of sleepiness and cognitive impairment during circadian misalignment when their internal clock promotes sleep during the patient's waking day(Sack et al., 2007b). Non-24h type is most common in blind individuals who have no photic input into the circadian clock. Psychiatric comorbidities are common in patients with non-24 h sleep disorder with some cases of mood disorders preceding and others following the onset of non-24 h (Hayakawa et al., 2005; Okawa and Uchiyama, 2007). Treatment with exogenous melatonin has been shown to entrain or synchronize patients with non- $24 \mathrm{~h}$ to the $24 \mathrm{~h}$ Earth day (Sack et al., 2007b).

\section{Shift work disorder (SWD)}

Chronic circadian misalignment often occurs during shift work schedules because the internal biological timekeeping system of most shift workers does not adapt to the imposed work schedule (Sack et al., 1992; Dumont et al., 2001). Working at a biological time when the circadian clock is promoting sleep leads to impaired cognitive function (Dijk and Czeisler, 1995) and results in poor job performance and an increased risk for accidents (Dinges, 1995; Åkerstedt, 1998; Åkerstedt et al., 2002). Individuals who are required to work during the biological night and who are most vulnerable to circadian misalignment are at risk for shift work disorder (Drake and Wright, 2011). In general, night shift, rotating and early morning shift work schedules result in circadian misalignment leading to impaired nighttime performance, contributing to reduced work productivity and increased risk of accidents (e.g., drowsy driving) and disturbed daytime sleep. Circadian misalignment is thought to be a primary factor contributing to the risk of shift work disorder. Figure 5 shows a model of circadian misalignment where daytime sleep is shorter 
Interaction Between Sleep Homeostasis and Circadian Phase Modulates Human Performance - Adverse Phase Relationship

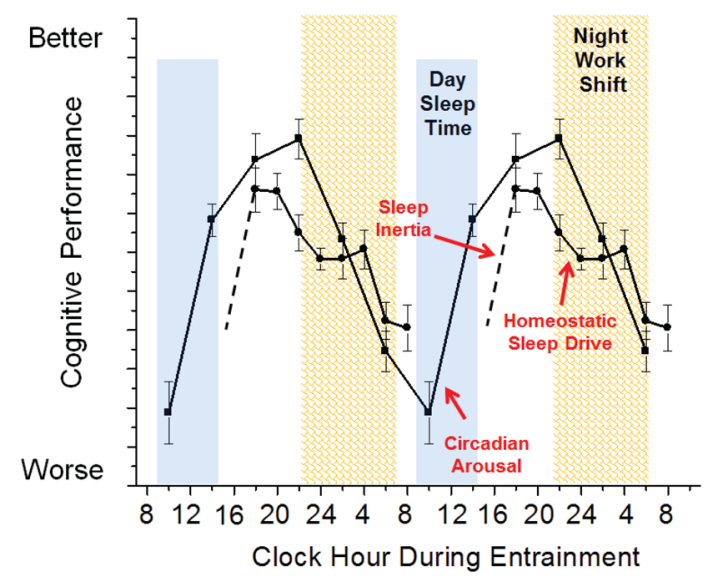

FIGURE 5 | Simplified model of wakefulness-sleep and circadian modulation of cognition during circadian misalignment associated with night work. Data are double plotted and show individual contributions of sleep inertia (grogginess upon awakening from sleep), homeostatic sleep drive (time awake and prior sleep history) and circadian phase (internal biological time) modulation of cognitive function. The interaction between sleep inertia, homeostatic sleep drive and circadian phase are altered during night shift work as compared to day work shown in Figure $\mathbf{3}$ such that sleepiness is promoted during the work shift.

\section{Integrative Control Systems of Neurocognitive and Neuroaffective Function}

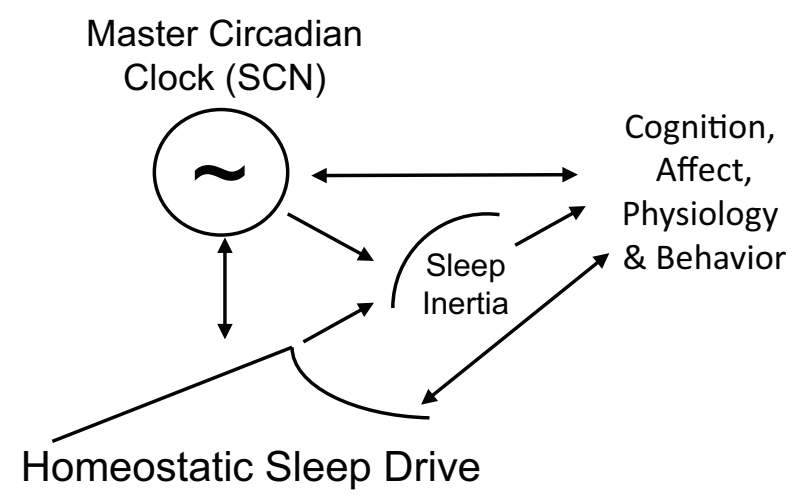

FIGURE 6 | Schematic of the integration of sleep inertia, sleep homeostatic and circadian control systems that modulate cognition, affect, physiology and behavior. Homeostatic sleep drive, circadian rhythms and sleep inertia all interact to influence human cognition, physiology and behavior. Arrows represent direction of influence. Circadian phase and homeostatic sleep drive interact to influence each other and both processes modulate sleep inertia. All three processes independently, and perhaps interactively, influence cognition, affect, physiology, and behavior. Behavior also feeds back to alter sleep homeostasis (e.g., choice to sleep versus engage in other activities) and circadian physiology (e.g., gating of exposure to light). than that during a typical nighttime sleep episode because the circadian clock promotes wakefulness after a few hours of sleep. Sleep inertia initially impairs cognition following awakening yet following the dissipation of sleep inertia, cognition would remain at relatively high levels because homeostatic sleep drive is relatively low and the circadian drive for arousal is high. However, during the nighttime work schedule both the sleep and circadian systems promote sleep and therefore represents a vulnerable time of cognitive impairment. This model illustrates one example of circadian misalignment as the circadian phase of shift workers could occur at other times than shown. Patients with SWD report mood problems such as impatience and avoidance of interaction with coworkers (Waage et al., 2009) and have a higher risk of poor sleep and depression (Drake et al., 2004). Sleep, mood and performance problems are not typically seen when sleep occurs at night and wakefulness occurs during the day (e.g., during vacation) but when there is a mismatch between sleep and circadian physiology and environmental time, mood and cognitive function are disturbed. Circadian adaption to the work-rest schedule theoretically can reverse these symptoms. Wakefulness and sleep promoting strategies can improve function (Czeisler et al., 2005), yet there is need to develop treatment strategies that restore nighttime cognition to daytime levels.

In conclusion, brain processes involved in wakefulness-sleep and circadian regulation are important for optimal cognitive and affective function (Figure 6). Proper alignment between wakefulness-sleep and circadian timing is critical for maintaining optimal function, psychological health and safety. Disturbed circadian and sleep physiology contribute to impaired cognitive and affective function in otherwise healthy people and in patients with circadian rhythms disorders. Cognitive and affective problems are common in children and adolescents when environmental challenges such as early school start times induce circadian and sleep disruption. Further research is needed to understand how challenges to sleep and circadian physiology, clock gene polymorphisms, and disruption of clock gene function in brain regions may contribute to cognitive and affective vulnerabilities during development, adulthood and with aging. For example, does disruption of clock genes in brain regions outside of the hippocampus disrupt performance? Do the circadian/sleep systems modulate sleepiness, cognitive function, and affective processing in childhood as they do in adults? The latter question may be most important in young children who are still napping and are developing more advanced emotion regulation and executive function strategies. Further research is also necessary to understand interactions between sleep and circadian processes on higher cognitive functions in humans and in non-human models. Lastly, development of effective treatment and countermeasure strategies for circadian misalignment represents an unmet need that has important implications for public health and safety.

\section{ACKNOWLEDGMENTS}

Preparation of this manuscript was supported in part by $\mathrm{NIH}$ R01HL085705, R01HL109706, R01MH086539, K01MH74643 and R01MH086566. We wish to thank Kevin J. Wright and Jamie Pfahl for assistance with figures. 


\section{REFERENCES}

Abe, M., Herzog, E. D., Yamazaki, S., Straume, M., Tei, H., Sakaki, Y., Menaker, M., and Block, G. D. (2002). Circadian rhythms in isolated brain regions. J. Neurosci. 22, 350-356.

Abrams, J. K., Johnson, P. L., Hollis, J. H., and Lowry, C. A. (2004). Anatomic and functional topography of the dorsal raphe nucleus. Ann. N.Y. Acad. Sci. 1018, 46-57.

Åkerstedt, T. (1998). Shift work and disturbed sleep/wakefulness. Sleep Med. Rev. 2, 117-128.

Åkerstedt, T., Fredlund, P., Gillberg, M., and Jansson, B. (2002). Work load and work hours in relation to disturbed sleep and fatigue in a large representative sample. J. Psychosom. Res. 53, 585-588.

Alam, M. N., Szymusiak, R., Gong, H., King, J., and McGinty, D. (1999). Adenosinergic modulation of rat basal forebrain neurons during sleep and waking: neuronal recording with microdialysis. J. Physiol. 521, 679-690.

Aston-Jones, G., and Bloom, F. E. (1981). Activity of norepinephrinecontaining locus coeruleus neurons in behaving rats anticipates fluctuations in the sleep-waking cycle. J. Neurosci. 1, 876-886.

Aston-Jones, G., Chen, S., Zhu, Y., and Oshinsky, M. L. (2001). A neural circuit for circadian regulation of arousal. Nat. Neurosci. 4, 732-738.

Aston-Jones, G., Shipley, M. T., Chouvet, G., Ennis, M., van Bockstaele, E., Pieribone, V., Shiekhattar, R., Akaoka, H. Drolet, G., Astier, B., Charléty, P., Valentino, R. J., and Williams, J. T. (1991). Afferent regulation of locus coeruleus neurons: anatomy, physiology and pharmacology. Prog. Brain Res. 88, 47-75.

Balkin, T. J., Braun, A. R., Wesensten, N. J., Jeffries, K., Varga, M., Baldwin, P., Belenky, G., and Herscovitch, P. (2002). The process of awakening: a PET study of regional brain activity patterns mediating the reestablishment of alertness and consciousness. Brain 125, 2308-2319.

Barger, L. K., Cade, B. E., Ayas, N. T., Cronin, J. W., Rosner, B., Speizer, F. E., Czeisler, C. A., and Harvard Work Hours, Health, and Safety Group. (2005). Extended work shifts and the risk of motor vehicle crashes among interns. $N$. Engl. J. Med. 352, 125-134.

Bayer, L., Eggermann, E., Serafin, M., Grivel, J., Machard, D., Muhlethaler, M., and Jones, B. E. (2005). Opposite effects of noradrenaline and acetylcholine upon hypocretin/orexin versus melanin concentrating hormone neurons in rat hypothalamic slices. Neuroscience 130, 807-811.

Boivin, D. B., Czeisler, C. A., Dijk, D. J., Duffy, J. F., Folkard, S., Minors, D. S., Totterdell, P., and Waterhouse, J. M. (1997). Complex interaction of the sleep-wake cycle and circadian phase modulates mood in healthy subjects. Arch. Gen. Psychiatry 54, 145-152.

Brabant, C., Alleva, L., Quertemont, E., and Tirelli, E. (2010). Involvement of the brain histaminergic system in addiction and addiction-related behaviors: a comprehensive review with emphasis on the potential therapeutic use of histaminergic compounds in drug dependence. Prog. Neurobiol. 92, 421-441.

Brown, R. E., Sergeeva, O. A., Eriksson, K. S., and Haas, H. L. (2002). Convergent excitation of dorsal raphe serotonin neurons by multiple arousal systems (orexin/hypocretin, histamine and noradrenaline). J. Neurosci. 22, 8850-8859.

Brown, R. E., Stevens, D. R., and Haas, H. L. (2001). The physiology of brain histamine. Prog. Neurobiol. 63 637-672.

Buhr, E. D., Yoo, S. H., and Takahashi, J. S. (2010). Temperature as a universal resetting cue for mammalian circadian oscillators. Science 330 , 379-385.

Carskadon, M. A., Harvey, K., Duke, P., Anders, T. F., Litt, I. F., and Dement, W. C. (1980). Pubertal changes in daytime sleepiness. Sleep 2, 453-460.

Carskadon, M. A., Wolfson, A. R., Acebo, C., Tzischinsky, O., and Seifer, R. (1998). Adolescent sleep patterns, circadian timing, and sleepiness at a transition to early school days. Sleep 21, 871-881.

Cermakian, N., Lamont, E. W., Boudreau, P., and Boivin, D. B. (2011). Circadian clock gene expression in brain regions of alzheimer's disease patients and control subjects. J. Biol. Rhythms 26, 160-170.

Chamberlin, N. L., Arrigoni, E., Chou, T. C., Scammell, T. E., Greene, R. W., and Saper, C. B. (2003). Effects of adenosine on gabaergic synaptic inputs to identified ventrolateral preoptic neurons. Neuroscience 119, 913-918.

Chou, T. C., Bjorkum, A. A., Gaus, S. E., Lu, J., Scammell, T. E., and Saper, C. B. (2002). Afferents to the ventrolateral preoptic nucleus. $J$. Neurosci. 22, 977-990.
Chou, T. C., Scammell, T. E., Gooley, J. J., Gaus, S. E., Saper, C. B. and Lu, J. (2003). Critical role of dorsomedial hypothalamic nucleus in a wide range of behavioral circadian rhythms. J. Neurosci. 23, 10691-10702.

Cohen, D. A., Wang, W., Wyatt, J. K., Kronauer, R. E., Dijk, D. J., Czeisler, C. A., and Klerman, E. B. (2010). Uncovering residual effects of chronic sleep loss on human performance. Sci. Transl. Med. 2, 14ra3.

Crosby, B., Gryczkowski, M. LeBourgeois, M. K., Olmi, D., Rabian, B., and Harsh, J. R. (2006). Mid-sleep time and school readiness in black and white preschool children. Sleep 29, A78.

Crosby, B., LeBourgeois, M. K., and Harsh, J. (2005). Racial differences in reported napping and nocturnal sleep in 2-to 8-year-old children. Pediatrics 115, 225-232.

Czeisler, C. A., Dijk, D.-J., and Duffy, J. F. (1994). "Entrained phase of the circadian pacemaker serves to stabilize alertness and performance throughout the habitual waking day." in Sleep Onset: Normal and Abnormal Processes, eds R. D. Ogilvie and J. R. Harsh (Washington, DC: American Psychological Association), 89-110.

Czeisler, C. A., Walsh, J. K., Roth, T., Hughes, R. J., Wright, K. P., Kingsbury, L., Arora, S., Schwartz, J. R., Niebler, G. E., Dinges, D. F., and U.S. Modafinil in Shift Work Sleep Disorder Study Group. (2005). Modafinil for excessive sleepiness associated with shift-work sleep disorder. N. Engl. J. Med. 353 476-486.

Dagan, Y., Stein, D., Steinbock, M. Yovel, I., and Hallis, D. (1998). Frequency of delayed sleep phase syndrome among hospitalized adolescent psychiatric patients. J. Psychosom. Res. 45, 15-20.

Dai, J., Swaab, D. F., and Buijs, R. M. (1997). Distribution of vasopressin and vasoactive intestinal polypeptide (VIP) fibers in the human hypothalamus with special emphasis on suprachiasmatic nucleus efferent projections. $J$. Comp. Neurol. 383, 397-414.

Date, Y., Ueta, Y., Yamashita, H., Yamaguchi, H., Matsukura, S., Kangawa, K., Sakurai, T. Yanagisawa, M., and Nakazato, M. (1999). Orexins, orexigenic hypothalamic peptides, interact with autonomic, neuroendocrine and neuroregulatory systems. Proc. Natl. Acad. Sci. U.S.A. 96, 748-753.

Datta, S., and Siwek, D. F. (2002). Single cell activity patterns of pedunculopontine tegmentum neurons across the sleep-wake cycle in the freely moving rats. J. Neurosci. Res. 70, 611-621.

de Lecea, L., Kilduff, T. S., Peyron, C., Gao, X., Foye, P. E., Danielson, P. E., Fukuhara, C., Battenberg, E. L., Gautvik, V. T., Bartlett, F. S. 2nd, Frankel, W. N., van den Pol, A. N., Bloom, F. E., Gautvik, K. M., and Sutcliffe, J. G. (1998). The hypocretins: hypothalamus-specific peptides with neuroexcitatory activity. Proc. Natl. Acad. Sci. U.S.A. 95, 322-327.

Deurveilher, S., and Semba, K. (2003). Indirect projections from the suprachiasmatic nucleus to the median preoptic nucleus in rat. Brain Res. 987, 100-106.

Deurveilher, S., and Semba, K. (2005). Indirect projections from the suprachiasmatic nucleus to major arousal-promoting cell groups in rat: implications for the circadian control of behavioural state. Neuroscience 130, 165-183.

Dijk, D. J., and Czeisler, C. A. (1995). Contribution of the circadian pacemaker and the sleep homeostat to sleep propensity, sleep structure, electroencephalographic slow waves, and sleep spindle activity in humans. J. Neurosci. 15, 3526-3538.

Dinges, D. F. (1990). "Are you awake? Cognitive performance and reverie during the hypnopompic state." in Sleep And Cognition, eds R. Bootzin, J. Kihlstrom, and D. Schacter (Washington, DC: American Psychological Association), 159-175.

Dinges, D. F. (1995). An overview of sleepiness and accidents. J. Sleep Res. 4, 4-14.

Drake, C. L., Roehrs, T., Richardson, G. Walsh, J. K., and Roth, T. (2004). Shift work sleep disorder: prevalence and consequences beyond that of symptomatic day workers. Sleep 27, 1453-1462.

Drake, C. L., and Wright, K. P. Jr. (2011). "Shift work, shift work disorder, and jet lag," in Principles and Practice of Sleep Medicine, eds M. H. Kryger, T. Roth, and W. C. Dement 5 edn., (St. Louis: Saunders), 784-798.

Duffy, J. F., Cain, S. W., Chang, A. M., Phillips, A. J., Münch, M. Y., Gronfier, C., Wyatt, J. K., Dijk, D. J., Wright, K. P. Jr., and Czeisler, C. A. (2011). Quantification of behavior sackler colloquium: sex difference in the near-24-hour intrinsic period of the human circadian timing system. Proc. Natl. Acad. Sci. U.S.A. 108, 15602-15608. 
Duffy, J. F., Dijk, D. J., Hall, E. F., and Czeisler, C. A. (1999). Relationship of endogenous circadian melatonin and temperature rhythms to selfreported preference for morning or evening activity in young and older people. J. Investig. Med. 47, 141-150.

Duffy, J. F., Rimmer, D. W., and Czeisler, C. A. (2001). Association of intrinsic circadian period with morningness-eveningness, usual wake time, and circadian phase. Behav. Neurosci. 115, 895-899.

Dumont, M., Benhaberou-Brun, D., and Paquet, J. (2001). Profile of 24-h light exposure and circadian phase of melatonin secretion in night workers. J. Biol. Rhythms 16, 502-511.

Ebisawa, T., Uchiyama, M., Kajimura, N., Mishima, K., Kamei, Y., Katoh, M., Watanabe, T., Sekimoto, M., Shibui, K., Kim, K., Kudo, Y., Ozeki, Y., Sugishita, M., Toyoshima, R., Inoue, Y., Yamada, N., Nagase, T., Ozaki, N., Ohara, O., Ishida, N., Okawa, M., Takahashi, K., and Yamauchi, T. (2001). Association of structural polymorphisms in the human period 3 gene with delayed sleep phase syndrome. EMBO Rep. 2, 342-346.

Elmenhorst, D., Meyer, P. T., Winz, O. H., Matusch, A., Ermert, J., Coenen, H. H., Basheer, R., Haas, H. L., Zilles, K., and Bauer, A. (2007). Sleep deprivation increases A1 adenosine receptor binding in the human brain: a positron emission tomography study. J. Neurosci. 27, 2410-2415.

Frey, D. J., Fleshner, M., and Wright, K. P. Jr. (2007). The effects of 40 hours of total sleep deprivation on inflammatory markers in healthy young adults. Brain Behav. Immun. 21, 1050-1057.

Fuller, P. M., Saper, C. B., and Lu, J. (2007). The pontine REM switch: past and present. J. Physiol. 584, 735-741.

Garlo, K. G., Crossin, R. A., Carskadon, M. A., and LeBourgeois, M. K. (2008). Assessment of salivary dim light melatonin onset (DLMO) and reported sleep in preschool children. Sleep 31, A48.

Goel, N., Banks, S., Mignot, E., and Dinges, D. F. (2009). PER3 polymorphism predicts cumulative sleep homeostatic but not neurobehavioral changes to chronic partial sleep deprivation. PLoS One 4:e5874. doi: 10.1371/journal.pone.0005874

Grady, S., Aeschbach, D., Wright, K. P. Jr., and Czeisler, C. A. (2010). Effect of modafinil on impairments in neurobehavioral performance and learning associated with extended wakefulness and circadian misalignment. Neuropsychopharmacolgy 35, 1910-1920.

Greene, C. M., Bellgrove, M. A., Gill, M., and Robertson, I. H. (2009). Noradrenergic genotype predicts lapses in sustained attention. Neuropsychologia 47, 591-594.

Gronfier, C., Wright, K. P. Jr., Kronauer, R. E., and Czeisler, C. A. (2007). Entrainment of the human circadian pacemaker to longer-than-24h days. Proc. Natl. Acad. Sci. U.S.A. 104, 9081-9086.

Gooley, J. J., Lu, J., Fischer, D., and Saper, C. B. (2003). A broad role for melanopsin in nonvisual photoreception. J. Neurosci. 23, 7093-106.

Guilding, C., Hughes, A. T., Brown, T. M., Namvar, S., and Piggins, H. D. (2009). A riot of rhythms: neuronal and glial circadian oscillators in the mediobasal hypothalamus. Mol. Brain 2, 28.

Guilding, C., and Piggins, H. D. (2007). Challenging the omnipotence of the suprachiasmatic timekeeper: are circadian oscillators present throughout the mammalian brain? Eur. J. Neurosci. 25, 3195-3216.

Hagan, J. J., Leslie, R. A., Patel, S., Evans, M. L., Wattam, T. A., Holmes, S., Benham, C. D., Taylor, S. G., Routledge, C., Hemmati, P., Munton, R. P., Ashmeade, T. E., Shah, A. S., Hatcher, J. P., Hatcher, P. D., Jones, D. N., Smith, M. I., Piper, D. C., Hunter, A. J., Porter, R. A., and Upton, N. (1999). Orexin A activates locus coeruleus cell firing and increases arousal in the rat. Proc. Natl. Acad. Sci. U.S.A. 96, 10911-10916.

Hale, M. W., and Lowry, C. A. (2011). Functional topography of midbrain and pontine serotonergic systems: implications for synaptic regulation of serotonergic circuits. Psychopharmacol 213, 243-264.

Hannibal, J., and Fahrenkrug, J. (2004). Target areas innervated by PACAP-immunoreactive retinal ganglion cells. Cell Tissue Res. 316, 99-113.

Hassani, O. K., Henny, P., Lee, M. G., and Jones, B. E. (2010). GABAergic neurons intermingled with orexin and $\mathrm{MCH}$ neurons in the lateral hypothalamus discharge maximally during sleep. Eur. J. Neurosci. 32, 448-457.

Hayakawa, T., Uchiyama, M., Kamei, Y., Shibui, K., Tagaya, H., Asada, T., Okawa, M., Urata, J., and Takahashi, K. (2005). Clinical analyses of sighted patients with non-24-hour sleep-wake syndrome: a study of 57 consecutively diagnosed cases. Sleep 28, 945-952.
Henny, P., and Jones, B. E. (2006). Innervation of orexin/hypocretin neurons by GABAergic, glutamatergic or cholinergic basal forebrain terminals evidenced by immunostaining for presynaptic vesicular transporter and postsynaptic scaffolding proteins. J. Comp. Neurol. 499, 645-661.

Hohjoh, H., Takasu, M., Shishikura, K., Takahashi, Y., Honda, Y., and Tokunaga, K. (2003). Significant association of the arylalkylamine $\mathrm{N}$-acetyltransferase (AA-NAT) gene with delayed sleep phase syndrome. Neurogenetics 4, 151-153.

Horne, J. A., and Reyner, L. A. (1995). Sleep related vehicle accidents. $B M$ J 310, 565-567.

Horne, J. A., Reyner, L. A., and Barrett, P. R. (2003). Driving impairment due to sleepiness is exacerbated by low alcohol intake. Occup. Environ. Med. 60, 689-692.

Hsieh, K. C., Gvilia, I., Kumar, S., Uschakov, A., McGinty, D., Alam, M. N., and Szymusiak, R. (2011) c-Fos expression in neurons projecting from the preoptic and latera hypothalamic areas to the ventrolateral periaqueductal gray in relation to sleep states. Neuroscience 188 55-67.

Hull, J. T., Wright, K. P., and Czeisler, C. A. (2003). The influence of subjective alertness and motivation on human performance independent of circadian and homeostatic regulation. J. Biol. Rhythms 18 329-338.

Hughes, A. T., Guilding, C., and Piggins, H. D. (2011). Neuropeptide signaling differentially affects phase maintenance and rhythm generation in SCN and extra-SCN circadian oscillators. PLoS One 6:e18926. doi: 10.1371/journal.pone.0018926

Iglowstein, I., Jenni, O. G., Molinari, L., and Largo, R. H. (2003). Sleep duration from infancy to adolescence: reference values and generational trends. Pediatrics 111, 302-307.

Jenni, O. G., Achermann, P., and Carskadon, M. A. (2005). Homeostatic sleep regulation in adolescents. Sleep 28, 1446-1454.

Jenni, O. G., and LeBourgeois, M. K. (2006). Understanding sleep-wake behavior and sleep disorders in children: the value of a model. Curr Opin. Psychiatry 19, 282-287.

Jilg, A., Lesny, S., Peruzki, N., Schwegler, H., Selbach, O., Dehghani, F., and Stehle, J. H. (2010). Temporal dynamics of mouse hippocampal clock gene expression support memory processing. Hippocampus 20 377-388.
Johnson, P. L., Truitt, W., Fitz, S. D. Minick, P. E., Dietrich, A., Sanghani, S., Träskman-Bendz, L., Goddard, A. W., Brundin, L., and Shekhar, A. (2010). A key role for orexin in panic anxiety. Nat. Med. 16 111-149.

Jones, B. E. (2005). From waking to sleeping: neuronal and chemical substrates. Trends Pharmacol. Sci. 26, 578-586.

Jones, B. E. (2008). Modulation of cortical activation and behavioral arousal by cholinergic and orexinergic systems. Ann. N.Y. Acad. Sci. 1129, 26-34.

Kalsbeek, A., Fliers, E., Hofman, M. A., Swaab, D. F., and Buijs, R. M. (2010). Vasopressin and the output of the hypothalamic biological clock. J. Neuroendocrinol. 22, 362-372.

Karatsoreos, I. N., Bhagat, S., Bloss, E. B., Morrison, J. H., and McEwen, B. S. (2011). Disruption of circadian clocks has ramifications for metabolism, brain, and behavior. Proc. Natl. Acad. Sci. U.S.A. 108, 1657-1662.

Katz, G. (2011). Jet lag and psychotic disorders. Curr. Psychiatry Rep. 13, 187-192.

Katz, G., Durst, R., Zislin, Y., Barel, Y., and Knobler, H. Y. (2001). Psychiatric aspects of jet lag: review and hypothesis. Med. Hypotheses 56, 20-23.

Kerkhof, G. A., and van Dongen, H. P. (1996). Morning-type and eveningtype individuals differ in the phase position of their endogenous circadian oscillator. Neurosci. Lett. 218, 153-156.

Kohler, C. A., da Silva, W. C., Benetti, F., and Bonini, J. S. (2011). Histaminergic mechanisms for modulation of memory systems. Neural. Plast. 2011, 328602.

Krauchi, K., Cajochen, C., and WirzJustice, A. (1997). A relationship between heat loss and sleepiness: effects of postural change and melatonin administration. J. Appl. Physiol. 83, 134-139.

Krueger, J. M., Clinton, J. M., Winters, B. D., Zielinski, M. R., Taishi, P., Jewett, K. A., and Davis, C. J. (2011). Involvement of cytokines in slow wave sleep. Prog. Brain Res. 193, 39-47.

Landrigan, C. P., Rothschild, J. M., Cronin, J. W., Kaushal, R., Burdick, E., Katz, J. T., Lilly, C. M., Stone, P. H., Lockley, S. W., Bates, D. W., and Czeisler, C. A. (2004). Effect of reducing interns' work hours on serious medical errors in intensive care units. N. Engl. J. Med. 351, 1838-1848. 
Leak, R. K., and Moore, R. Y. (2001). Topographic organization of suprachiasmatic nucleus projection neurons. J. Comp. Neurol. 433, 312-334.

Lee, J. H., Wang, W., Silva, E. J., Chang, A. M., Scheuermaier, K. D., Cain, S. W., and Duffy, J. F. (2009). Neurobehavioral performance in young adults living on a 28-h day for 6 weeks. Sleep 32, 905-913.

Li, S. X., Liu, L. J., Jiang, W. G., and Lu, L. (2009). Morphine withdrawal produces circadian rhythm alterations of clock genes in mesolimbic brain areas and peripheral blood mononuclear cells in rats. J. Neurochem. 109, 1668-2679.

Liu, R. J., van den Pol, A. N., and Aghajanian, G. K. (2002). Hypocretins (orexins) regulate serotonin neurons in the dorsal raphe nucleus by excitatory direct and inhibitory indirect actions. $J$. Neurosci. 22, 9453-9464.

Lockley, S. W., Cronin, J. W., Evans, E. E., Cade, B. E., Lee, C. J., Landrigan, C. P., Rothschild, J. M., Katz, J. T., Lilly, C. M., Stone, P. H., Aeschbach, D., and Czeisler, C. A. Harvard Work Hours, Health, and Safety Group. (2004). Effect of reducing interns' weekly work hours on sleep and attentional failures. N. Engl. J. Med. 351, 1829-1837.

Lowry, C. A., Evans, A. K., Gasser, P. J., Hale, M. W., Staub, D. R., and Shekhar, A. (2008). "Topographical organization and chemoarchitecture of the dorsal raphe nucleus and the median raphe nucleus," in: Serotonin and Sleep: Molecular, Functional and Clinical Aspects, eds J. M. Monti, B. L. Pandi-Perumal, B. L. Jacobs, and D. L. Nutt (Basel: Birkhauser), 25-68.

Lowry, C. A., Hale, M. W., and Wright, K. P. (2010). "Stress and arousal/sleep." in Encyclopedia of Behavioral Neuroscience, eds G. F. Koob, M. Le Moal, and R. F. Thompson (Oxford: Academic Press), 295-303).

Lu, B. S., and Zee, P. C. (2006). Circadian rhythm sleep disorders. Chest 130, 1915-1923.

Lu, J., Greco, M. A., Shiromani, P., and Saper, C. B. (2000). Effect of lesions of the ventrolateral preoptic nucleus on NREM and REM sleep. J. Neurosci. 20, 3830-3842.

Luo, A. H., and Aston-Jones, G. (2009). Circuit projection from suprachiasmatic nucleus to ventral tegmental area: a novel circadian output pathway. Eur. J. Neurosci. 29, 748-760.

Lyznicki, J. M., Doege, T. C., Davis, R. M., and Williams, M. A. (1998).
Sleepiness, driving, and motor vehicle crashes. JAMA 279, 1908-1913.

Markwald, R. R., Lee-Chiong, T. L., Burke, T. M., Snider, J. A., and Wright, K. P. Jr. (2010). Effects of the melatonin MT-1/MT-2 agonist ramelteon on daytime body temperature and sleep. Sleep 33, 825-831.

Masubuchi, S., Honma, S., Abe, H., Ishizaki, K., Namihira, M., Ikeda, M., and Honma, K. (2000). Clock genes outside the suprachiasmatic nucleus involved in manifestation of locomotor activity rhythm in rats. Eur. J. Neurosci. 12, 4206-4214.

Matthews, R. W., Ferguson, S. A., Zhou, X., Kosmadopoulos, A., Kennaway, D. J., and Roach, G. D. (2012). Simulated driving under the influence of extended wake, time of day and sleep restriction. Accid. Anal. Prev. 45, 55-61.

McCarley, R. W. (2007). Neurobiology of REM and NREM sleep. Sleep Med. 8, 302-330.

McCormick, D. A., and Bal, T. (1997). Sleep and arousal: thalamocortical mechanisms. Annu. Rev. Neurosci. 20, 185-215.

Mongrain, V., Lavoie, S., Selmaoui, B., Paquet, J., and Dumont, M. (2004). Phase relationships between sleep-wake cycle and underlying circadian rhythms in morningnesseveningness. J. Biol. Rhythms 19, 248-257.

Monti, J. M., and Monti, D. (2007). The involvement of dopamine in the modulation of sleep and waking. Sleep Med. Rev. 11, 113-133.

Murray, G., Nicholas, C. L., Kleiman, J., Dwyer, R., Carrington, M. J., Allen, N. B., and Trinder, J. (2009). Nature's clocks and human mood: the circadian system modulates reward motivation. Emotion 9, 705-716.

Namihira, M., Honma, S., Abe, H., Tanahashi, Y., Ikeda, M., and Honma, K. (1999). Daily variation and light responsiveness of mammalian clock gene, Clock and BMAL1, transcripts in the pineal body and different areas of brain in rats. Neurosci. Lett. 267, 69-72.

Nitz, D., and Siegel, J. (1997). GABA release in the dorsal raphe nucleus: role in the control of REM sleep. Am. J. Physiol. 273, R451-R455.

Okawa, M., and Uchiyama, M. (2007). Circadian rhythm sleep disorders: characteristics and entrainment pathology in delayed sleep phase and non-24 sleep-wake syndrome. Sleep Med. Rev. 11, 485-496.

Owens, J. A., Belon, K., and Moss, P. (2010). Impact of delaying school start time on adolescent sleep, mood, and behavior. Arch. Pediatr. Adolesc. Med. 164, 608-614.

Pack, A. I., Pack, A. M., Rodgman, E., Cucchiara, A., Dinges, D F., and Schwab, C. W. (1995) Characteristics of crashes attributed to the driver having fallen asleep. Accid. Anal. Prev. 27, 769-775.

Passani, M. B., Blandina, P., and Torrealba, F. (2011). The histamine $\mathrm{H} 3$ receptor and eating behavior. $J$. Pharmacol. Exp. Ther. 336, 24-29.

Peyron, C., Tighe, D. K., van den Pol, A. N., de Lecea, L., Heller, H. C., Sutcliffe, J. G., and Kilduff, T. S. (1998). Neurons containing hypocretin (orexin) project to multiple neuronal systems. J. Neurosci. 18, 9996-10015.

Porkka-Heiskanen, T., Strecker, R. E., Thakkar, M., Bjorkum, A. A., Greene, R. W., and McCarley, R. W. (1997). Adenosine: a mediator of the sleep-inducing effects of prolonged wakefulness. Science 276, 1265-1268.

Rai, S., Kumar, S., Alam, M. A. Szymusiak, R., McGinty, D., and Alam, M. N. (2010). A(1) receptor mediated adenosinergic regulation of perifornical-lateral hypothalamic area neurons in freely behaving rats. Neuroscience 167, 40-48.

Rainnie, D. G., Grunze, H. C. McCarley, R. W., and Greene, R. W. (1994). Adenosine inhibition of mesopontine cholinergic neurons: implications for EEG arousal. Science 263, 689-692.

Rajaratnam, S. M., Polymeropoulos, M H., Fisher, D. M., Roth, T., Scott, C., Birznieks, G., and Klerman, E. B. (2009a). Melatonin agonist tasimelteon (VEC-162) for transient insomnia after sleep-time shift: two randomised controlled multicentre trials. Lancet 373, 482-491.

Rajaratnam, S. M. W., Choen, D. A. and Rogers, N. L. (2009b). Melatonin and melatonin analogues. Sleep Med. Clin. 4, 179-193.

Reid, K. J., and Zee, P. C. (2009). Circadian rhythm disorders. Semin Neurol. 29, 393-405.

Rosenwasser, A. M. (2010). Circadian clock genes: non-circadian roles in sleep, addiction, and psychiatric disorders? Neurosci. Biobehav. Rev. 34, 1249-1255.

Sack, R. L., Auckley, D., Auger, R. R., Carskadon, M. A., Wright, K P. Jr., Vitiello, M. V., Zhdanova, I. V., and American Academy of Sleep Medicine. (2007a). Circadian rhythm sleep disorders: part i, basic principles, shift work and jet lag disorders: an american academy of sleep medicine review. Sleep 30, 1456-1479.
Sack, R. L., Auckley, D., Auger, R. R., Carskadon, M. A., Wright, K. P. Jr., Vitiello, M. V., Zhdanova, I. V., and American Academy of Sleep Medicine. (2007b). Circadian rhythm sleep disorders: part ii, advanced sleep phase disorder, delayed sleep phase disorder, freerunning disorder, and irregular sleep-wake rhythm: an american academy of sleep medicine review. Sleep 30, 1480-1497.

Sack, R. L., Blood, M. L., and Lewy, A. J. (1992). Melatonin rhythms in night shift workers. Sleep 15, 434-441.

Sakai, K., and Crochet, S. (2001). Differentiation of presumed serotonergic dorsal raphe neurons in relation to behavior and wake-sleep states. Neuroscience 104, 1141-1155.

Saper, C. B., Fuller, P. M., Pedersen, N. P., Lu, J., and Scammell, T. E. (2010). Sleep state switching. Neuron 68, 1023-1042.

Saper, C. B., Lu, J., Chou, T. C., and Gooley, J. (2005). The hypothalamic integrator for circadian rhythms. Trends Neurosci. 28, 152-157.

Saper, C. B., Scammell, T. E., and Lu, J. (2005). Hypothalamic regulation of sleep and circadian rhythms. Nature 437, 1257-1263.

Scheer, F. A., Shea, T. J., Hilton, M. F., and Shea, S. A. (2008). An endogenous circadian rhythm in sleep inertia results in greatest cognitive impairment upon awakening during the biological night. J. Biol. Rhythms 23, 353-361.

Schepens, B., Stapley, P., and Drew, T. (2008). Neurons in the pontomedullary reticular formation signal posture and movement both as an integrated behavior and independently. J. Neurophysiol. 100, 2235-2253.

Shen, H., and Semba, K. A. (1994). Direct retinal projection to the dorsal raphe nucleus in the rat. Brain Res. 635, 159-68.

Shouse, M. N., Staba, R. J., Saquib, S. F., and Farber, P. R. (2000). Monoamines and sleep: microdialysis findings in pons and amygdala. Brain Res. 860, 181-189.

Silva, E. J., and Duffy, J. F. (2008). Sleep inertia varies with circadian phase and sleep stage in older adults. Behav. Neurosci. 122, 928-935.

Silva, E. J., Wang, W., Ronda, J. M., Wyatt, J. K., and Duffy, J. F. (2010). Circadian and wakedependent influences on subjective sleepiness, cognitive throughput, and reaction time performance in older and young adults. Sleep 33 , 481-490.

Soffin, E. M., Gill, C. H., Brough, S. J., Jerman, J. C., and Davies, C. H. 
(2004). Pharmacological characterisation of the orexin receptor subtype mediating postsynaptic excitation in the rat dorsal raphe nucleus. Neuropharmacolgy 46, 1168-1176.

Steriade, M. (1992). Basic mechanisms of sleep generation. Neurol 42, 9-17.

Stiles, J., and Jernigan, T. L. (2010). The basics of brain development. Neuropsychol. Rev. 20, 327-348.

Strecker, R. E., Morairty, S., Thakkar, M. M., Porkka-Heiskanen, T., Basheer, R., Dauphin, L. J., Rainnie, D. G., Portas, C. M., Greene, R. W., and McCarley, R. W. (2000). Adenosinergic modulation of basal forebrain and preoptic/anterior hypothalamic neuronal activity in the control of behavioral state. Behav. Brain Res. 115, 183-204.

Szymusiak, R., Gvilia, I., and McGinty, D. (2007). Hypothalamic control of sleep. Sleep Med. 8, 291-301.

Szymusiak, R., and McGinty, D. (2008). Hypothalamic regulation of sleep and arousal. Ann. N.Y. Acad. Sci. 1129, 275-286.

Takahashi, K., Wang, Q. P., Guan, J. L., Kayama, Y., Shioda, S., and Koyama, Y. (2005). State-dependent effects of orexins on the serotonergic dorsal raphe neurons in the rat. Regul. Pept. 126, 43-47.

Takano, A., Uchiyama, M., Kajimura, N., Mishima, K., Inoue, Y., Kamei, Y., Kitajima, T., Shibui, K., Katoh, M., Watanabe, T., Hashimotodani, Y., Nakajima, T., Ozeki, Y., Hori, T., Yamada, N., Toyoshima, R., Ozaki, N., Okawa, M., Nagai, K., Takahashi, K., Isojima, Y., Yamauchi, T., and Ebisawa, T. (2004). A missense variation in human casein kinase I epsilon gene that induces functional alteration and shows an inverse association with circadian rhythm sleep disorders. Neuropsychopharmacology 29, 1901-1909.

Teclemariam-Mesbah, R., Ter Horst, G. J., Postema, F., Wortel, J., and Buijs, R. M. (1999). Anatomical demonstration of the suprachiasmatic nucleus-pineal pathway. J. Comp. Neurol. 406, 171-182.

Toh, K. L., Jones, C. R., He, Y., Eide, E. J., Hinz, W. A., Virshup, D. M., Ptácek, L. J., and Fu, Y. H. (2001). An hPer2 phosphorylation site mutation in familial advanced sleep phase syndrome. Science 291, 1040-1043.

Tully, K., and Bolshakov, V. Y. (2010). Emotional enhancement of memory: how norepinephrine enables synaptic plasticity. Mol. Brain. 3, 15.

Uchiyama, M., and Lockley, S. W. (2009). Non-24-hour sleep-wake syndrome in sighted and blind patients. Sleep Med. Clin. 4, 195-211.

Uschakov, A., Gong, H., McGinty, D., and Szymusiak, R. (2007). Efferent projections from the median preoptic nucleus to sleep- and arousalregulatory nuclei in the rat brain. Neuroscience 150, 104-120.

Valdez, P., Ramirez, C., Garcia, A., Talamantes, J., and Cortez, J. (2010). Circadian and homeostatic variation in sustained attention. Chronobiol. Int. 27, 393-416.

van der Heijden, K. B., de Sonneville, L. M. J., and Althaus, M. (2010). Timeof-day effects on cognition in preadolescents: a trails study. Chronobiol. Int. 27, 1870-1894.

van Someren, E. J. W. (2000). More than a marker: interaction between the circadian regulation of temperature and sleep, age-related changes, and treatment possibilities. Chronobiol. Int. 17, 313-354.

Vgontzas, A. N., Zoumakis, E., Bixler, E. O., Lin, H. M., Follett, H., Kales, A., and Chrousos, G. P. (2004). Adverse effects of modest sleep restriction on sleepiness, performance, and inflammatory cytokines. J. Clin. Endocrinol. Metab. 89, 2119-2126.

Viola, A. U., Archer, S. N., James, L. M., Groeger, J. A., Lo, J. C., Skene, D. J., von Schantz, M., and Dijk, D. J. (2007). PER3 polymorphism predicts sleep structure and waking performance. Curr. Biol. 17, 613-618.

Vorona, R. D., Szklo-Coxe, M., Wu, A., Dubik, M., Zhao, Y. Q., and Ware, J. C. (2011). Dissimilar teen crash rates in two neighboring southeastern virginia cities with different high school start times. J. Clin. Sleep Med. 7, U145-U181.

Waage, S., Moen, B. E., Pallesen, S., Eriksen, H. R., Ursin, H., Åkerstedt, T., and Bjorvatn, B. (2009). Shift work disorder among oil rig workers in the North Sea. Sleep 32, 558-565.

Wahlstrom, K. (2010). School start time and sleepy teens. Arch. Pediatr. Adolesc. Med. 164, 676-677.

Wakamatsu, H., Yoshinobu, Y., Aida, R., Moriya, T., Akiyama, M., and Shibata, S. (2001). Restrictedfeeding-induced anticipatory activity rhythm is associated with a phase-shift of the expression of mPer1 and mPer2 mRNA in the cerebral cortex and hippocampus but not in the suprachiasmatic nucleus of mice. Eur. J. Neurosci. 13, 1190-1196.

Wang, L. M., Dragich, J. M., Kudo, T., Odom, I. H., Welsh, D. K., O’Dell, T. J., and Colwell, C. S. (2009).
Expression of the circadian clock gene Period2 in the hippocampus: possible implications for synaptic plasticity and learned behaviour. ASN Neuro. 1. pii: e00012.

Wertz, A. T., Ronda, J. M., Czeisler, C. A., and Wright, K. P. Jr. (2006). Effects of sleep inertia on cognition. JAMA 295, 163-164.

Wolfson, A. R., Spaulding, N. L., Dandrow, C., and Baroni, E. M. (2007). Middle school start times: the importance of a good night's sleep for young adolescents. Behav. Sleep Med. 5, 194-209.

Wright, K. P. Jr., Badia, P., and Wauquier, A. (1995). Topographical and temporal patterns of brain activity during the transition from wakefulness to sleep. Sleep 18, 880-889.

Wright, K. P. Jr., Drake, C. L., and Lockley, S. W. (2008). "Diagnostic tools for circadian rhythm sleep disorders." in Handbook of Sleep Disorders, ed C. A. Kushida (New York, NY: Taylor and Francis Group), 147-175.

Wright, K. P. Jr., Gronfier, C., Duffy, J. E., and Czeisler, C. A. (2005). Intrinsic period and light intensity determine the phase relationship between melatonin and sleep in humans. J. Biol. Rhythms 20, 168-177.

Wright, K. P. Jr., Hughes, R. J., Kronauer, R. E., Dijk, D. J., and Czeisler, C. A. (2001). Intrinsic near-24-h pacemaker period determines limits of circadian entrainment to a weak synchronizer in humans. Proc. Natl. Acad. Sci. U.S.A. 98, 14027-14032.

Wright, K. P. Jr., Hull, J. T., and Czeisler, C. A. (2002). Relationship between alertness, performance, and body temperature in humans. Am. J. Physiol. 283, R1370-R1377.

Wright, K. P. Jr., Hull, J. T., Hughes, R. J., Ronda, J. M., and Czeisler, C. A. (2006). Sleep and wakefulness out of phase with internal biological time impairs learning in humans. J. Cogn Neurosci. 18, 508-521.

Wyatt, J. K., Cajochen, C., Ritz-De Cecco, A., Czeisler, C. A., and Dijk, D. J. (2004). Low-dose repeated caffeine administration for circadian-phase-dependent performance degradation during extended wakefulness. Sleep 27 374-381.

Wyatt, J. K., Dijk, D. J., Ritz-De Cecco, A., Ronda, J. M., and Czeisler, C. A. (2006). Sleep-facilitating effect of exogenous melatonin in healthy young men and women is circadianphase dependent. Sleep 29, 609-618.
Yamazaki, S., Numano, R., Abe, M. Hida, A., Takahashi, R., Ueda, M. Block, G. D., Sakaki, Y., Menaker, M., and Tei, H. (2000). Resetting central and peripheral circadian oscillators in transgenic rats. Science 288, 682-685.

Yanai, K., and Tashiro, M. (2007). The physiological and pathophysiological roles of neuronal histamine: an insight from human positron emission tomography studies. Pharmacol. Ther. 113, $1-15$.

Zhou, X., Ferguson, S. A., Matthews, R. W., Sargent, C., Darwent, D., Kennaway, D. J., and Roach, G. D. (2011a). Dynamics of neurobehavioral performance variability under forced desynchrony: evidence of state instability. Sleep 34, 57-63.

Zhou, X., Ferguson, S. A., Matthews, R. W., Sargent, C., Darwent, D., Kennaway, D. J., and Roach, G. D. (2011b). Sleep, wake and phase dependent changes in neurobehavioral function under forced desynchrony. Sleep 34, 931-941.

Zhou, X., Ferguson, S. A., Matthews, R. W., Sargent, C., Darwent, D., Kennaway, D. J., and Roach, G. D. (2012). Mismatch between subjective alertness and objective performance under sleep restriction is greatest during the biological night. J. Sleep Res. 21, 40-9.

Conflict of Interest Statement: Dr. Wright has been a consultant for Takeda Pharmaceuticals of North America, Zeo, Inc., Johnson and Johnson Inc., and has served as Chair of the external advisory board of Northwestern University American Waterways Operators Towboat Project, and serves as Chair of the scientific advisory board of Zeo, Inc. and has stock options from Zeo, Inc.

Received: 23 October 2011; accepted: 27 March 2012; published online: 18 April 2012.

Citation: Wright KP, Lowry CA and LeBourgeois MK (2012) Circadian and wakefulness-sleep modulation of cognition in humans. Front. Mol. Neurosci. 5:50. doi: 10.3389/fnmol.2012.00050 Copyright (c) 2012 Wright, Lowry and LeBourgeois. This is an openaccess article distributed under the terms of the Creative Commons Attribution Non Commercial License, which permits non-commercial use, distribution, and reproduction in other forums, provided the original authors and source are credited. 